\title{
SISTEM PREDIKSI SAHAM MENGGUNAKAN ADAPTIVE NEURO FUZZY INFERENCE SYSTEM (STUDI KASUS SAHAM MINGGUAN PT ASTRA AGRO LESTARI, TBK)
}

\author{
Yuniar Farida, S.T, M.T ${ }^{1)}$ \\ Program Studi Matematika Fakultas Sains dan Teknologi \\ Universitas Islam Negeri Sunan Ampel \\ Email : greatyuniar@gmail.com
}

\begin{abstract}
Abstrak
Informasi mengenai harga saham sangat dibutuhkan oleh investor karena pembelian saham akan dilakukan pada saat harga rendah dan sebaliknya penjualan saham dilakukan pada saat harga tinggi. Untuk memprediksi perubahan harga-harga saham di setiap periode dapat dilakukan penelitian sebagai acuan bagi investor dan manajemen perusahaan dalam mengambil keputusan. Metode yang digunakan untuk memprediksi yaitu metode Adaptive Neuro Fuzzy Inference System (ANFIS).

Pada penelitian ini metode ANFIS diimplementasikan dengan struktur standar ANFIS yaitu lima layer. Namun sebagai data inputan dianalisis menggunakan analisis time series. Kemudian dihitung RSME sistem prediksi tersebut menggunakan data training dan data testing yang diambil secara acak.

Hasil perhitungan RSME dalam proses prediksi diharapkan mengetahui pengolahan data untuk time series begitupun untuk mendapatkan error terkecil sebesar 0,001.
\end{abstract}

Kata Kunci: prediksi saham, data time series, ANFIS

\begin{abstract}
Information on the share price is needed by the investor for the purchase of shares will be made at the time of low prices and vice versa stock sales made at the time of high prices. To predict changes in stock prices in each period to do research as a reference for investors and company management in decision making. The method used to predict the method of Adaptive Neuro Fuzzy Inference System (ANFIS).

In this study, ANFIS method is implemented with the standard structure of ANFIS are five layers. However, as the input data were analyzed using time series analysis. RSME then calculated the prediction system using training data and testing data is drawn at random.

RSME calculation results in a process expected to know the prediction for time series data processing as well as to get the smallest error of 0.001 .
\end{abstract}

Keywords: prediksi saham, data time series, ANFIS

\section{PENDAHULUAN}

Alternatif untuk menjaga dan meningkatkan kekayaan, salah satunya dengan media investasi berupa saham. Harga saham di Indonesia dapat mengalami perubahan dan rentang terhadap beberapa periode, misalnya periode setiap hari, minggu, bulan dan tahun. Informasi harga saham sangat dibutuhkan oleh investor karena pembelian saham akan dilakukan pada saat harga rendah dan sebaliknya penjualan saham dilakukan pada saat harga tinggi. Untuk memprediksi perubahan harga-harga saham di setiap periode dapat dilakukan penelitian sebagai acuan bagi investor dan manajemen perusahaan dalam mengambil keputusan. Hasil prediksi yang akurat diperlukan dalam proses pengambilan keputusan yang tepat.

Sistem prediksi saham telah banyak diteliti antara lain akurasi prediksi harga saham antm menggunakan metode regresi linier ganda versus Arima [1]. Juga telah digunakan teknik jaringan syaraf tiruan Feedforward untuk prediksi harga saham pada pasar modal indonesia [2]. Dan prediksi saham bank Centra Asia dengan metode Markov Chain [3]. Ada pula klasifikasi sinyal EEG menggunakan metode fuzzy C-Mens clustering dan adaptive neighborhood 
modified backpropagation[4] . Tetapi dalam penelitian ini menggunakan metode Adaptive Neuro Fuzzy Inference System (ANFIS) .

ANFIS adalah metode yang sering digunakan untuk prediksi atau diagnosis. ANFIS merupakan gabungan dua sistem yaitu neural network dan fuzzy logic. Neural Network atau disebut juga Jaringan saraf tiruan ialah suatu struktur yang meniru keberadaan sel-sel saraf (neuron) sebagaimana dalam otak manusia. Sistem saraf tiruan memberikan kemudahkan dalam mengklasifikasikan suatu objek. Berdasarkan masukan sistem, Fuzzy logic merupakan pemakaian fungsi keanggotaan untuk menentukan seberapa besar suatu predikat memenuhi suatu fungsi yang dinyatakan kedalam "if - then" yang memberi kemudahan dengan tidak memerlukan analisis matematik untuk pemodelan. Metode ANFIS terdiri 5 lapisan, yang setiap lapisannya memiliki perlakuan yang berbeda [5][10].

Pokok permasalahan dari penelitian ini adalah membuat suatu sistem dengan ANFIS untuk memprediksi harga saham mingguan PT Astra Agro Lestari,Tbk. Sebagai masukannya, menggunakan berbagai macam kombinasi harga seperti: harga pembukaan, tertinggi, terendah, dan penutupan. Diharapkan dengan menggunakan ANFIS, sistem peramalan untuk saham dapat dilakukan dengan baik.

\section{TINJAUAN PUSTAKA}

\subsection{Data Penelitian}

Data penelitian berupa harga saham, harga saham merupakan market clearing prices yang ditentukan berdasarkan kekuatan permintaan dan penawaran. Bahkan dinyatakan juga bahwa fluktuasi harga saham disebabkan oleh pilihan dan tingkah laku dari segala hal yang terlibat di pasar, suasana psikologi yang ada dipasar, kondisi ekonomi makro, perkembangan industri, kondisi politik, dan sebagainya [1]. Sebagai contoh data harga saham pada PT. Astra Agro Lestari, Tbk. Data ini berupa harga saham pada saat pembukaan, tertinggi, terendah dan penutuan.

Tabel 1. Sampel Data Saham pada PT. Astra Agro Lestari, Tbk.

\begin{tabular}{|c|c|c|c|c|}
\hline Tanggal & $\begin{array}{c}\text { Pembuka } \\
\text { an }\end{array}$ & $\begin{array}{c}\text { Terting } \\
\text { gi }\end{array}$ & $\begin{array}{c}\text { Terenda } \\
\text { h }\end{array}$ & $\begin{array}{c}\text { Penutupa } \\
\mathrm{n}\end{array}$ \\
\hline $\begin{array}{c}2-01- \\
2015\end{array}$ & 24300 & 25000 & 24250 & 24575 \\
\hline $\begin{array}{c}5-01- \\
2015\end{array}$ & 24600 & 26150 & 24175 & 25975 \\
\hline $\begin{array}{c}12-01- \\
2015\end{array}$ & 25900 & 26000 & 24550 & 24725 \\
\hline $\begin{array}{c}19-01- \\
2015\end{array}$ & 24750 & 24850 & 23775 & 24000 \\
\hline $\begin{array}{c}26-01- \\
2015\end{array}$ & 24000 & 24425 & 23150 & 23250 \\
\hline
\end{tabular}

\subsection{Time Series}

Time series merupakan sekumpulan data yang dicatat dalam satu periode waktu. Time series ini digunakan untuk peramalan atau forecasting [6]. Dalam melakukan analisis time series pertama yang dilakukan mengetahui pola data yang digunakan. Pada umumnya ada 4 tipe pola data pada time series yaitu: horisontal, trend, musiman dan siklis.

\subsection{Logika Fuzzy}

Fuzzy didefinisikan sebagai sesuatu yang samar atau kabur, samar, tidak jelas, membingungkan. Penggunaan istilah sistem fuzzy tidak dimaksudkan untuk mengacu pada sebuah sistem yang tidak jelas definisi, cara kerjanya, atau deskripsinya akan tetapi sitem fuzzy yang dimaksud adalah sistem yang dibangun dengan definisi, cara kerja, dan deskripsi yang jelas berdasarkan teori logika fuzzy. Logika fuzzy adalah metodologi untuk memetakan permasalahan dari input menuju ke output dengan variabel kata-kata (linguistic variable). Tiga hal yang digunakan untuk dasar-dasar logika fuzzy, yaitu: himpunan fuzzy, fungsi keanggotaan (membership function), dan operasi logika [7][11].

\subsection{ANFIS}

ANFIS adalah arsitektur yang secara fungsional sama dengan fuzzy rule base model Sugeno. Arsitektur ANFIS sama dengan jaringan saraf dengan fungsi radial dengan sedikit batasan tertentu. Dapat dikatakan bahwa ANFIS adalah suatu metode yang dalam melakukan penyetelan aturan digunakan algoritma pembelajaran terhadap sekumpulan data. Parameter ANFIS terbagi menjadi dua, yaitu parameter premis dan konsekuensi yang dapat diadaptasikan dengan algoritma hybrid [8][10].

Gambar 1 adalah arsitektur ANFIS dengan beberapa komponen. Komponen tersebut adalah simpul-simpul pada arsitektur ANFIS [9]:

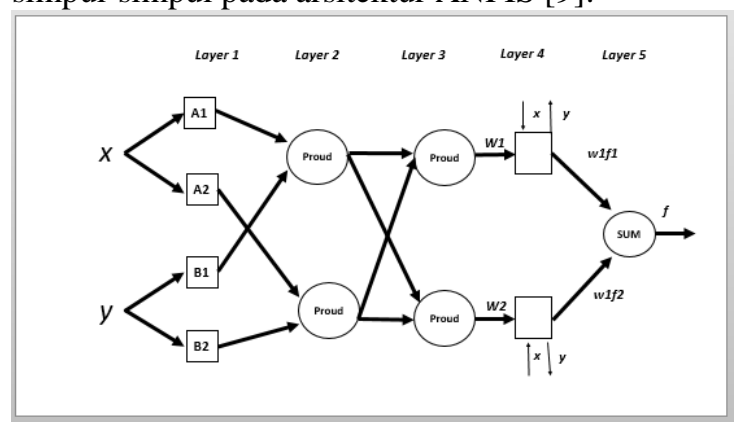

\section{Gambar 1. Arsiktektur Jaringan ANFIS}

\section{Layer 1}

Tiap-tiap neuron i pada lapaisan pertama adaptif terhadap parameter suatu fungsi aktivasi. Output dari tiap neuron berupa derajat keanggotaan yang diberikan oleh fungsi keanggotaan input, yaitu:

$\mathrm{n} 1 \mathrm{a}=\operatorname{Bell}(\mathrm{x} ; \mathrm{a} 1, \mathrm{~b} 1, \mathrm{c} 1)$

$\mathrm{n} 2 \mathrm{a}=\operatorname{Bell}(\mathrm{x} ; \mathrm{a} 2, \mathrm{~b} 2, \mathrm{c} 2)$ 
dimana $x$ adalah masukan bagi simpul n1a, dan n2a, sedangakan a1, b1, c1, a2, b2, c2 adalah parameter tingkatan keanggotaan dari himpunan fuzzy A dan menentukan derajad keanggotaan dari masukan $x$ yang diberikan. Fungsi keanggotaan parameter dari $A$ dapat diketahui dengan fungsi bell:

$$
\mu_{\mathrm{A} 1}=\frac{1}{1+\left[\left(\frac{x-c i}{a i}\right)^{2}\right]^{b}}
$$

Dimana $\{a i$, bi, ci $\}$ adalah himpunan parameter, parameter pada lapisan ini disebut parameterparameter premis.

\section{Layer 2}

Setiap simpul pada lapisan ini diberi label n3a dan $\mathrm{n} 4 \mathrm{a}$, bersifat non-adaptif (parameter tetap) yang meneruskan hasil dari lapisan ke-1. Karena sistem yang digunakan satu input, maka tidak ada inferensi AND. Dengan demikian keluaran pada lapisan-2 adalah:

$$
\begin{aligned}
& \mathrm{n} 3 \mathrm{a}=\mathrm{n} 1 \mathrm{a} \\
& \mathrm{n} 4 \mathrm{a}=\mathrm{n} 2 \mathrm{a}
\end{aligned}
$$

\section{Layer 3}

Setiap simpul pada lapisan ini diberi label n5a dan n6a, juga bersifat non adaptif. Masing-masing simpul menampilkan derajad pengaktifan ternormalisasi dengan bentuk.

$$
\begin{aligned}
& \mathrm{n} 5 \mathrm{a}=\frac{n 3 a}{(n 3 a+n 4 a)} \\
& \mathrm{n} 6 \mathrm{a}=\frac{n 4 a}{(n 3 a+n 4 a)}
\end{aligned}
$$

\section{Layer 4}

Tiap simpul pada lapisan ini berupa simpul adaptif, dan pada lapisan ini diperoleh matriks A, sebagai berikut:

$$
\mathrm{A}=\left[\begin{array}{cccc}
(\mathrm{n} 5 \mathrm{a}) \times(\mathrm{i}) & (\mathrm{n} 5 \mathrm{a}) & (\mathrm{n} 6 \mathrm{a}) \times(\mathrm{i}) & (\mathrm{n} 6 \mathrm{a}) \\
\mathrm{a} & \mathrm{x} & \mathrm{x} & \mathrm{x} \\
(\mathrm{n} 5 \mathrm{a}) \times(\mathrm{n}) & (\mathrm{n} 5 \mathrm{a}) & (\mathrm{n} 6 \mathrm{a}) \times(\mathrm{n}) & (\mathrm{n} 6 \mathrm{a})
\end{array}\right]
$$

Jumlah baris matriks A sebanyak jumlah data input $\mathrm{x}$. Pada lapisan ini dicari nilai parameter konsekuen $\emptyset$ dengan metode LSE. Persamaan metode LSE dinyatakan pada persamaan 9 .

$$
\theta=\operatorname{inv}\left(A^{T} A\right) A^{T} \cdot y
$$

Dengan $\mathrm{y}=$ output target yang diinginkan.

$$
\theta=[p 1 q 1 p 2 q 2]^{T}
$$

Selanjutnya untuk menghitung keluaran keluaran di lapisan ke-4 digunakan persamaan 11 dan persamaan 12.

$$
\begin{aligned}
& \mathrm{n} 7 \mathrm{a}=\mathrm{p} 1 * \mathrm{x}+\mathrm{q} 1 \\
& \mathrm{n} 8 \mathrm{a}=\mathrm{p} 2 * \mathrm{x}+\mathrm{q} 2
\end{aligned}
$$

\section{Layer 5}

Simpul tunggal pada lapisan ini diberi label n9a, yang mana menghitung semua keluaran sebagai penjumlahan dari semua sinyal yang masuk, seperti persamaan 13 .

$$
\mathrm{n} 9 \mathrm{a}=\mathrm{n} 7 \mathrm{a}+\mathrm{n} 8 \mathrm{a}
$$

\section{METODE PENELITIAN}

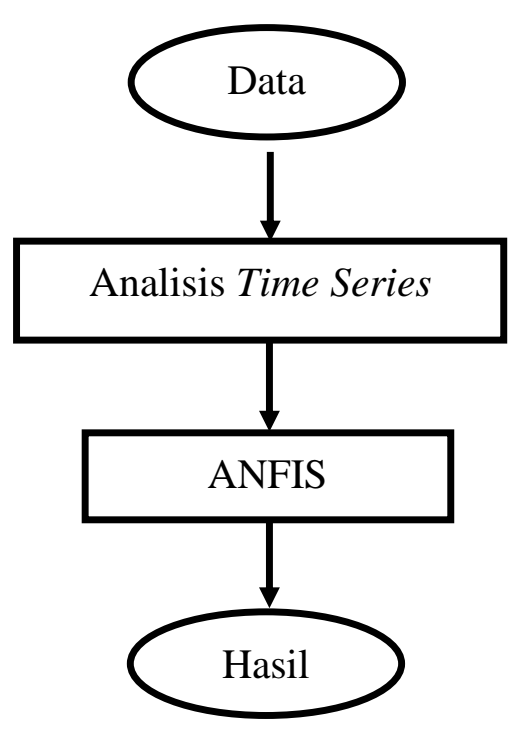

\section{Gambar 2. Algoritma Penelitian}

Langkah-langkah dari proses ini dijelaskan sebagai berikut:

1. Input sistem menggunakan analisis time series yaitu mengetahui tipe pola data saham tersebut dengan cara memploting data asli. Setelah diketahui maka data tersebut diselesaikan menggunakan metode ratarata bergerak tunggal (single moving average) menjadi data inputan. Dalam hal ini data harga saham mingguan ditransformasikan kebentukan bulanan dengan prediksi $(\mathrm{t}+4)$, $\mathrm{t}$ tersebut menyatakan waktu.

2. Implementasi ANFIS untuk prediksi harga saham. Sistem prediksi saham ini memiliki beberapa tahapan dan langkah-langkah sebagai berikut:

a. Tahap pertama adalah meng-inputkan data harga saham mingguan yang sudah dianalisis menggunakan time series.

b. Tahap selanjutnya adalah melakukan pelatihan dengan menggunakan algoritma pembelajaran ANFIS. Pada tahap ini data diambil secara acak data testing melalui 5 layer.

c. Setelah dilakukan pelatihan dan didapatkan kondisi jaringan yang optimal, dilakukan pengujian dengan menggunakan nilai parameter jaringan dari hasil pelatihan.

d. Menampilkan keluaran akhir dari perhitungan ANFIS berupa prediksi harga saham.

3. Perhitungan Akurasi.

Data-data yang di jadikan sebagai data pelatihan dan data pengujian dilakukan perhitungan RSME dan akurasi dengan menggunakan persamaan 14 .

$$
\mathrm{RSME}=\sqrt{\frac{\sum_{i=1}^{N}(y i-\bar{y} i)}{N}}
$$


Dimana $\mathrm{N}$ adalah banyaknya data, yi adalah target jaringan dan ỹi adalah output jaringan.

\section{HASIL DAN PEMBAHASAN}

Data awal dianalisis menggunakan time series. Dari ploting tersebut terlihat bahwa data tersebut berpola horisontal. Kemudian di analisis menggunakan metode rata-rata bergerak tunggal untuk inputan data ke metode selanjutnya yaitu metode ANFIS.

\subsection{Implementasi ANFIS}

Setelah data dianalisis menggunakan time series, data di implementasikan ke ANFIS nilai inputan nya dua dan outputannya satu. Untuk implementasi ANFIS dalam sistem prediksi dilakukan training dan testing. Dalam hal ini harga saham dapat diprediksi. Berikut data realita dan peramalan. Sistem ini dibatasi dengan 0.001 untuk error maksimal dan 100 untuk iterasi maksimal. Dan rulebase sangat mempengaruhi dalam proses prediksi untuk menentukan eror terkecil. Dalam penelitian ini digunakan 64 rulebase .

Keluaran dari Layer 1 berupa derajat keanggotaan yang sesuai dengan parameter yang sesuai dengan persamaan (1) dan (2). Layer 2 aturan-aturan. Pada layer 2 ini tidak menggunakan aturan aturan karena data inputan nya hanya satu yaitu harga saham saja maka outputan nya langsung dari layer 1 yaitu pada persamaan (4) dan (5) . Kemudian layer 3 normalisasi yang terdapat pada persamaan (6) dan (7). Setelah itu layer 4 ialah deffuzifikasi yaitu mencari parameter yang nilai keluarannya melalui persamaan (11) dan (12). Kemudian layer 5, pada layer ini semua sinyal yang masih dijumlahkan sesuai dengan persamaan (13). Berikut Gambar 4 hasil input dan output pada ANFIS yang melalui 5 layer.

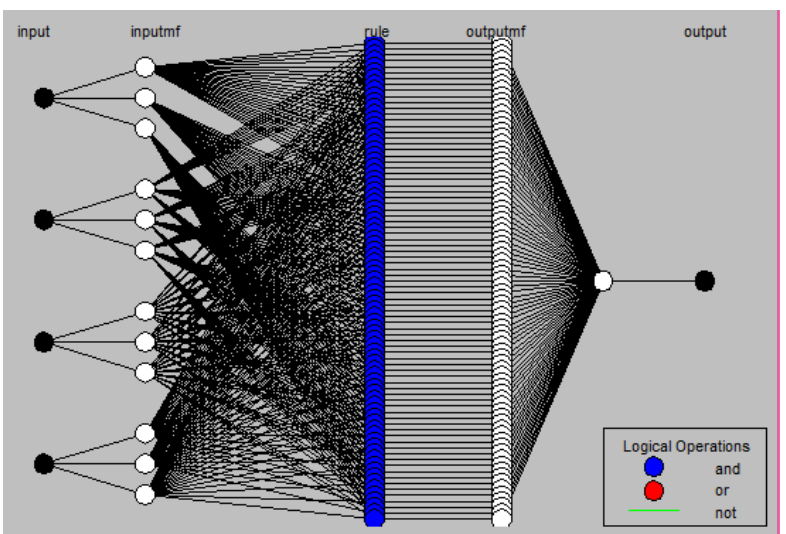

Gambar 4. Hasil input-output ANFIS
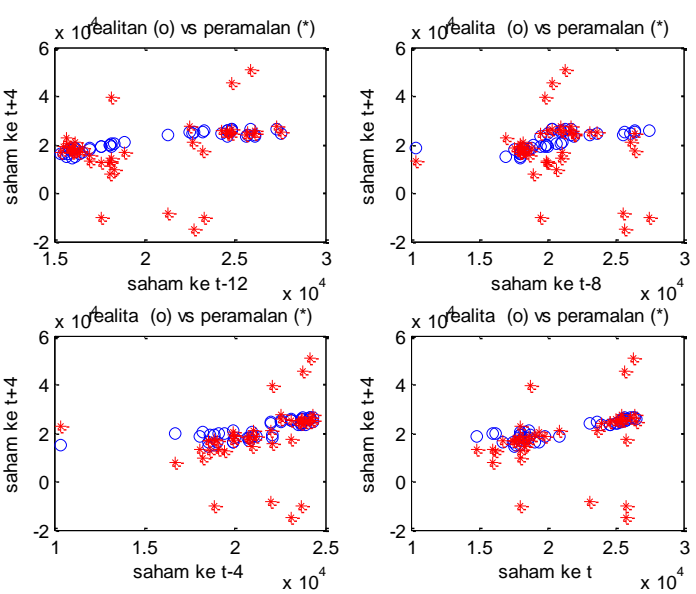

Gambar 5. Ploting hasil

training realita dengan peramalan

Pada Gambar 5 dan 6 merupakan salah satu hasil training yang diambil 48 data dan testing yang diambil 8 data, warna biru menunjukkan nilai realita atau nilai data asli. Sedangkan warna merah menunjukkan nilai peramalan. Maka diketahui nilai RSME nya sebesar 1,244.
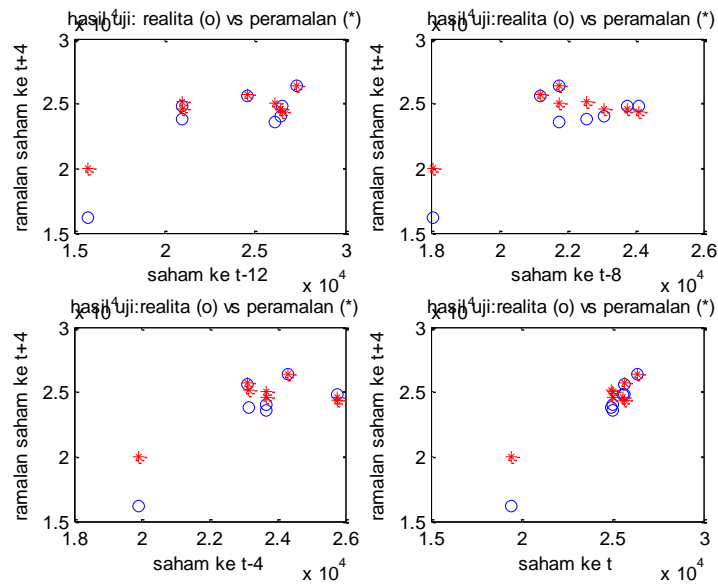

Gambar 6. Ploting hasil testing realita dengan peramalan
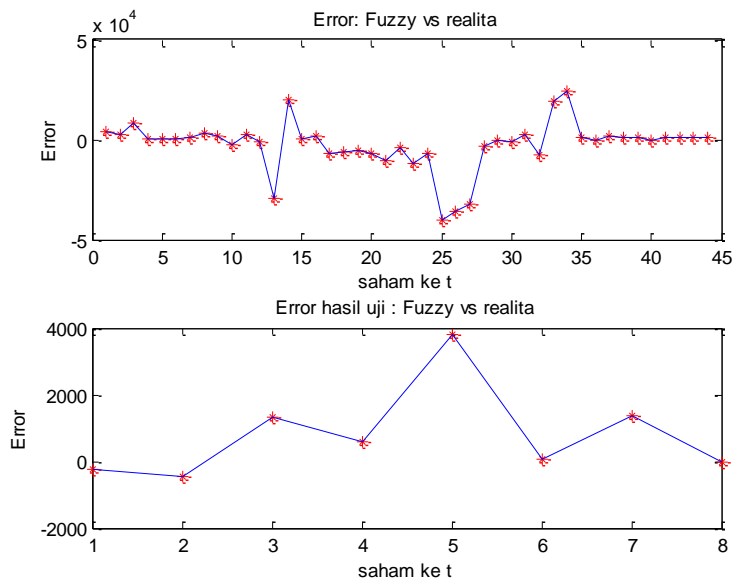

Gambar 7. Ploting hasil eror tes dan uji realita dengan peramalan

Pada Gambar 7 menunjukkan perbedaan salah satu hasil nilai eror pada data testing dan training. 
Untuk perhitungan akurasi dalam sistem prediksi maka data yang digunakan peneliti terdapat 53 data. Dalam perhitungan akurasi dilakukan pengujian RSME. Untuk pengujian tersebut diambil dara training dan testing secara random. Hasil pengujian ditunjukkan pada Tabel 1.

\begin{tabular}{|c|c|l|}
\hline $\begin{array}{l}\text { Data } \\
\text { Training }\end{array}$ & $\begin{array}{l}\text { Data } \\
\text { Testing }\end{array}$ & RSME \\
\hline 29 & 24 & 1,364 \\
\hline 42 & 13 & 1,354 \\
\hline 48 & 5 & 1,384 \\
\hline 44 & 8 & 1,244 \\
\hline
\end{tabular}

\section{KESIMPULAN}

Dari hasil dan pembahasan sistem prediksi saham menggunakan adaptive neuro fuzzy inference system. Dapat disimpulkan bahwa untuk proses prediksi diharapkan mengetahui pengolahan data untuk time series begitupun untuk mendapatkan error terkecil sebesar 0,001 .

\section{DAFTAR PUSTAKA}

[1] Handoyo,S.E. Rahardjo,T.H. Hindardjo,A. "Akurasi Prediksi Saham ANTM menggunakan Metode Regresi Linier Ganda Versus Arima",jurnal ekonomi.

[2] Bambang, B.DP. Widodo, R.J. Singgih M.L.” Teknik Jaringan Syaraf Tiruan Feedforward untuk Prediksi Harga Saham pada Pasar Modal Indonesia”. Jurnal Informatika Vol. 1, No. 1, 1999 : 11 - 22.

[3] Nur Cahyo, S. Pringgowati,A. Rofiqo H. "Prediksi Saham Bank Centra Asia dengan Metode Markov Chain".2013.

[4] Novitasari Dian C.R. " Klasifikasi Sinyal EEG menggunakan Metode C-Means Clustering (FCM) dan Adaptive Neighborhood Modified Backpropagation (ANMBP).

[5] Dewi Candra. Kartika, D.P. Mursityo, Y.T. " Prediksi Cuaca pada Data Time Series Menggunakan Adaptive Neuro Fuzzy Inference System (ANFIS)".Universitas Brawijaya.

[6] Harish Ahmad Nur. " Analisis Time Series". http://mainartikel.blogspot.co.id/2014/12/analisistime-series.html.. 24 Juni 2016.

[7] Kuncahyo, B.T. Ginardi H.R.V. Arieshanti. “ Penerapan Metode Adaptive Neuro-Fuzzy Inference System untuk Memprediksi Nilai Post Test Mahasiswa pada Jurusan Informatika FTIF ITS". Makalah Seminar Tugas Akhir Periode Januari 2012

[8] Fitriah A. Abadi A.M. 2011 “ Aplikasi Model Neuro Fuzzy untuk Prediksi Tingkat Inflasi di Indonesia”. Makalah Seminar Nasional Matematika dan Pendidikan Matematika.

[9] Pramudijanto, J. Effendi, N.I. Purnomo, M.H. “ Implementasi Adaptive Neuro Fuzzy Inference
System(ANFIS) pada Pengaturan Kecepatan Servomotor MS150DC ".

[10] Novitasari, Dian Candra Rini. Klasifikasi Sinyal EEG Menggunakan Metode Fuzzy C-Means (FCM) dan Adaptive Neuro Fuzzy Inference System (ANFIS). Thesis. Teknik Informatika ITS. 2013

[11]Novitasari Dian C.R. " Pengklasteran Lahan Sawah di Indonesia sebagai Evaluasi Ketersediaan Produksi Pangan Menggunakan Fuzzy C-Means", Jurnal Matematika MANTIK Vol 2 No 12016. 